\title{
MODELING CORRUPTION AS A CONTAGIOUS DISEASE
}

\author{
Jaderick P. Pabico* \\ Institute of Computer Science \\ University of the Philippines Los Baños \\ *jppabico@up.edu.ph
}

\begin{abstract}
A system of ordinary differential equations (ODEs) was developed to model the interaction dynamics between public servants and the citizens they serve to provide insights to the evolution of corruption in the public service. Corruption is modeled as a contagious disease that can "infect" susceptible citizens when they interact with "infected" (i.e., corrupt) public servants through harassment bribery. In this model, the public servants and the citizens are compartmentalized into different classes. The public servants could be honest (SH), on a crossroad (SX), corrupt (SC), or dismissed (SD), while citizens could either be upright (CU), apathetic (CA), cooperators (CC), or whistleblowers (CW). SH do not ask for harassment bribery while SX have asked for harassment bribery but only choose which citizen to ask from. SC always ask for harassment bribery no matter what, while SD have been dismissed from public service (and prosecuted) as a result of complaints. CU and CA do not give bribery but the former always complain when public servants ask for them, while the later do not do anything. $\mathrm{CC}$ and $\mathrm{CW}$ give bribery but the former willingly give them, while the later grudgingly give them and then complain. The ODEs provide for intra- and inter-action dynamics between the public servants and citizens with probabilities of interactions among actors as parameters of the model. Various combinations of interaction probability values provide for scenarios when corruption in the form of harassment bribery will become contagious, epidemic, and self-correcting (i.e., self-healing).
\end{abstract}

Keywords: corruption, bribery, modeling, public servant, citizen

\section{INTRODUCTION}

Corruption is a social problem that persists in most organizations (Corruption Perception Index, 2018), particularly in the government where public servants are perceived with influence or power of some kind and are expected to provide some service to the citizens they serve. Transparency International adopted the technical definition by Eicher (2009): "Corruption is the abuse of entrusted power for private gain." Corruption in the public service results in revenue losses for the government, degradation of social justice, violation of human rights, and exploitation of vulnerable people (Verma and Sengupta, 2015). One example of losses in government revenue is undervaluing a private property tax as computed by a public servant to favor the property owner in exchange for some kind of payment that is paid directly to the public servant. Here, if the correct tax for a property is $T$, the public servant undervalues the tax to only $t$, such that $t<T$ or worse $t<<T$, but a portion $\rho$ of the savings gained by the owner (where $0<\rho$ $\leq 1$ ) is paid directly to the public servant resulting to the public servant personally (albeit 
illegally) earning an easy amount equivalent to $\rho(T-t)$ and the owner saving $(1-\rho)(T-t)$. Notice here that when $\rho=1$, the difference $T-t$ goes wholely to the public servant and the owner receives nothing. In any case, the government loses what is technically termed as illicit financial outflow (Global Financial Integrity, 2018) in the amount $T-t$ which are shared both by the public servant with a factor of $\rho$ and by the property owner with a factor of $(1-\rho)$. In this scenario, the public servant clearly abused her ${ }^{1}$ power to gain an amount of money for herself.

In the above example, because the public servant was rewarded with an easy amount equivalent to $\rho(T-t)$, she may form some sort of bias to prefer to serve property owners with larger $T$ first, and delay the service to those with smaller $T$. This is because even with a linearly proportionate $t$ and the same $\rho$, her reward is bigger, and by serving those with bigger $T$ first, the accumulation of bigger rewards is faster. This preferential bias by a corrupt public servant results in the degradation of social justice because the citizens who are perceived with more to offer are given preference over those with less, while those with less are discriminated against. Here, preferential bias is technically similar to confirmatory bias (Plous, 1993) or myside bias (Baron, 2007) defined in the field of cognitive psychology. When public servants use preferential bias as a way to serve their constituents, the rights of the public to receive equal treatment and service are violated. Citizens who do not know or are not aware of their rights may even be at risk of exploitation by the public servant, maybe as in the case when $\rho=1$.

Facilitated by crime and corruption, the Philippine government lost a total of about USD 410.50B (or equivalently PHP 19.34T on 2014 FOREX with 0 inflation) between 1960 and 2011, as estimated by Kar and LeBlanc (2014) through a 52-year computer simulation of illicit financial flow. These loses, although reportedly had driven the underground economy, resulted in reduced government domestic revenues and further worsen corruption (Gascoigne and Fajan, 2014; Kar and Spanjers, 2015). Over the 52-year time span, a major portion of money that was lost by the Philippines through illicit financial flow is mostly due to misinvoicing of products by as much as 25\% less of the actual amount (Kar and Spanjers, 2015; Rey, 2016). This means that for every $T$ that the government is supposed to earn per transaction, the government only receives $t=0.75 T$, and the corrupt public servant earns as much as $0.25 T$. According to Rey (2016), the government lost USD 3.865B in tax revenues in 2011 (or equivalently PHP 166.74B on that year's FOREX rates), which is about $10 \%$ of the national budget for that year (R.A.10147).

Of the estimated $1.3 \mathrm{M}$ government employees, $63.6 \%$ of these are bureaucrats with national responsibility, $29.2 \%$ are local servants, and 7.2\% are employees of government-owned and/or controlled corporations (Civil Service Commission, 2010). Since most public services are provided at the local level, if all of the 380,000 local servants benefited from these estimated loses, then each public servant would have earned an average of PHP440K for that year. However, a study of the Office of the Ombudsman (2014) shows that only 4\% of the sampled government transactions have reportedly illicit financial flow. Assuming that these 4\% were conducted at the local level, then corrupt local public servants received a shocking estimated average of PHP 11M each for that year.

1 Note that the use of the female pronoun in this text is just a matter of writing style and is not a means to prejudice either sex.

JP Pabico/Modeling Corruption as a Contagious Disease

Page 2 of 22 
Wealth, whether legally or illegally, obtained is not really uniformly distributed among populations in any social structure (Souma, 2001; Di Matteo, et al., 2004; Banerjee and Yakovenko, 2010). In fact, according to the 1992 UN Development Program Report, a Champagne Glass Effect (also known as fat-tailed Pareto-Law) describes the worldwide wealth distribution such that $82.7 \%$ of a country's wealth is owned by the richest $20 \%$ of the population, while only $1.4 \%$ of the wealth is shared by the poorest $20 \%$. Because the population of public servants is within the same social structure, it is safe to assume that this $80-20$ rule is also reflected among the estimated $4 \%$ corrupt public servants. In this case, the top $20 \%$ corrupt public servants gained a much more shocking estimated average of PHP 45M each in 2011 alone, while the bottom $20 \%$ gained an estimated PHP 769K each. Even at the bottom case, the wealth gained illegally in the public service is still staggering especially when compared to the average wealth gain of PHP $69 \mathrm{~K}$ each by citizens belonging to the poorest $10 \%$ of the population (Ericta, 2013).

With such staggering accumulation of wealth via illegal ways, one might ask the question how such a culture of impunity persist in the public service right in the full view of the citizens and their co-workers? Did it start with only a few bad bananas which made the whole bunch rotten? Was it aided by apathy and lack of activism among the citizens who experienced it the first time? Was it because of bystander bias (Darley and Latane, 1968) that the citizen failed to help a fellow citizen when she witnessed that the public servant was demanding a bribe from that fellow? Similarly, was it also aided by peer influence (Mason, et al., 2009) among the public servants that even the honest ones would not squeal on their fellows? Assuming that the public service profession started out with a relatively clean slate "seeded" with only a few bad bananas, how did it evolve into a state that is perceived to be corrupt in general?

In this paper, the evolution of corruption in the public service is studied through the dynamics of interaction between the public servants and the citizens they serve. The interaction dynamics is defined by a system of ordinary differential equations (ODEs) that describes the transformation of public servants to and from being honest (SH), on a crossroad (SX), corrupted (SC), and dismissed (SD) as they interact with one another and with the citizens they serve. Additionally, the ODEs also describe the transformation of citizens to and from being upright (CU), apathetic $(\mathrm{CA})$, cooperators $(\mathrm{CC})$, and whistleblowers $(\mathrm{CW})$ as they interact with one another and with the public servants.

Honest public servants ( $\mathrm{SH})$ are those who provide public service without asking for bribes and are not willing to receive bribes for any reason. Public servants on a crossroads (SX) are those who have asked for bribes from citizens whom they perceived have the capacity to pay and are also willing to receive bribes from time to time. Corrupt public servants (SC) are those who will ask for bribes all the time and are willing to receive bribes anytime. Dismissed public servants (SD) are those who have been permanently disqualified from holding a government position and, as a result of complaints from citizens, had been meted out with finality by the court of law the penalties described in Section Two, Article 210 or 211 of the Revise Penal Code (RPC). Upright citizens (CU) are those who will not offer bribes, will not pay bribes, and will always complain if a public servant demands for bribes. Apathetic citizens (CA) are somewhat similar to CU with a difference of being apathetical if a public servant demands for bribes. Citizens who cooperate (CC) are those who will pay bribes if a public servant demands for it and will not complain. 
Whistleblowers (CW) are citizens who will pay bribes if a public servant demands for it but will complain to the authorities.

The rate of transformation from one class to the other is defined by coefficients to the variables in the ODE. The variables in the ODE are the respective population counts of the different public servants and citizens as defined by functions with respect to time $t$. Governmental policies and prevailing cultural biases within the public service can be simulated via the parameters to the model, which are transformation rates that allow one individual to transform from one class to the other. For example, a governmental policy that allows a culture of corruption to flourish by not punishing bribery can easily allow a public servant to transform from SH to SX and eventually to SC via their interaction with one another and with the citizens they serve. Similarly, the same policy will allow citizens to transform from $\mathrm{CU}$ to $\mathrm{CC}$ because there is no benefit from staying $\mathrm{CU}$ within a culture of corruption and there are more benefits to being $\mathrm{CC}$. With the model, one can show how policies and culture will enable or disable the disease-like propagation of corruption in the public service.

\section{LITERATURE REVIEW}

\section{A. Bribery Classes}

Although corruption in the public service is manifested in many forms, a much pervasive and damaging variant involves what the Office of the Ombudsman (2014) called petty or bureaucratic corruption or simply bribery. Just like any form of corruption, bribery results to undermining the financial and democratic aspects of the government and the moral values of its people (Verma and Sengupta, 2015). Financial-wise, bribery leads to substantial government revenue losses while it erodes the people's faith in democratically installed public institutions to implement fair services and effect moral values.

Bribery comes into two kinds: Harassment Bribery and Collusive Bribery. Harassment bribery (Basu, 2011) happens when a public servant directly or indirecty asks for favors (monetary or in kind) from a citizen in exchange for a government service and the citizen willingly or grudgingly gives them. This is in contrast to collusive bribery (also called facilitation payment) which happens when a citizen voluntarily gives a public servant favors (without being asked for them) in exchange for a government service and the public servant willingly accepts them. In the Philippines, harassment bribes $\left(\mathrm{B}_{\mathrm{H}}\right)$ are known by its many names: lagay, suhol, tong, kotong, tongpats, and komisyon. Collusive bribes $\left(\mathrm{B}_{\mathrm{C}}\right)$ are called grease money, padulas, tip, pakimkim, and langis (Office of the Ombudsman, 2014). In both harassment and collusive bribery, defined respectively as Direct and Indirect Bribery in the RPC, the public servant when found guilty by a court of law is penalized under Section Two, Articles 210 and 211, respectively, of the RPC (Act No. 3815). The citizen who paid the bribe in either case, termed as Corruption of Public Official in the RPC, is also penalized with the same penalty as the public servant under Section Two, Article 212.

\section{B. Punishment Regimes}

The Philippines' RPC is a kind of criminal punishment legislation that does not discriminate who 
initiated the bribery. Notice that harassment bribery is initiated by the public servant, while collusive bribery is initiated by the citizen. The public servant and the citizen are both guilty of the same crime because both participated in the crime. The citizen willingly or grudgingly paid the bribe as in the case of harassment bribery, and the public servant willingly accepted the bribe as in the case of collusive bribery. Both kinds of bribery have equal penalties for both the public servant and the citizen, with an additional light penalty of special temporary disqualification for the public servant (Section Two, Article 210 of RPC). The implementation of criminal laws in several countries can be categorized as symmetric or asymmetric punishment (Engel, et al., 2013). In symmetric punishment (SP), the public servant who asked for or received the bribe and the citizen who willingly or grudgingly gave the bribe are both given the same penalties. This type of criminal law is implemented in countries like the Philippines, U.S.A., U.K., France, and India. In asymmetric punishment (AP), the public servant who asked for or received the bribe receives a greater punishment than the willing or grudging citizen who paid the bribe. China, Japan and Russia are examples of countries with AP criminal justice system.

Basu (2011), in his analysis of bribery cases in India, argued that incidents of harassment briberies will be greatly reduced if the citizen who willingly or grudgingly gave the $\mathrm{B}_{\mathrm{H}}$ is not penalized. Remember that in harassment bribery, the public servant who asked for $\mathrm{B}_{\mathrm{H}}$ is the initiator of the crime. The argument for the total asymmetric punishment (TAP) would encourage citizens to report incidents of harassment bribery. In TAP, the public servant who asked for or was given the bribe is the only one punished and not the willing or grudging citizen who paid or offered the bribe. This thereby increases the likelihood of public servants being prosecuted for bribery, which will discourage them from demanding for $\mathrm{B}_{\mathrm{H}}$ or willingly receiving $\mathrm{B}_{\mathrm{C}}$. In due time, this will lead to reduction of harassment bribery incidents. Even if the expected outcome in TAP is desired, counter-arguments to the actual implementation of Basu's proposed policy initiative exist, particularly on the moral side (Dreze, 2011).

In a simulated study involving deterministic and stochastic evolutionary game-theoretic models of bribery, Verma and Sengupta (2015) found that the policy total asymmetric punishment with reward (TAPR) can significantly reduce the incidence of harassment bribery, but in the long run depends on the long-term game-theoretic strategies of the public servants, the citizens involved, and the government policies in effect. Various government policies such as varying the amount of the reward from a certain portion of the bribe paid to the full amount paid as bribe plus some other cost of reporting the bribery incident were considered. In TAPR, the government financially rewards the citizen who paid the bribe, reported the bribery incident to the authorities, and the government successfully prosecuting the public servant who received or asked for the bribe. As in SP, reporting the bribery incident to the authorities incurs a cost to the citizen who reported the incident.

\section{Laboratory Studies of Bribery}

Using laboratory settings, Abbink, et al. (2002) have initiated experimental studies on understanding the evolution of collusive bribery for the purpose of recommending policies to reduce its incidence in the public service. The studies were later on followed-up and extended by several researchers (Abbink, 2006; Banuri and Eckel, 2012; Serra and Wantchekon, 2012). In these studies, several aspects of collusive bribery were analyzed and as a result various policy 
measures were suggested to reduce, if not to totally irradicate, the illegal practice of offering $\mathrm{B}_{\mathrm{C}}$ to public servants (Abbink, 2004; Schickora, 2011; Serra, 2011). Some behavioral studies under laboratory settings found that framing effect plays a major role among citizens in deciding whether or not to offer $\mathrm{B}_{\mathrm{C}}$ (Abbink and Hennig-Schmidt, 2006; Barr and Serra, 2009). Framing effect is a cognitive bias (Plous, 1993) where one chooses to offer $B_{C}$ if the final effect of paying for it is presented as a gain for her (e.g., receiving the service at a lower cost without being criminally prosecuted for offering $\mathrm{B}_{\mathrm{C}}$ ), but chooses not to if the final effect is presented otherwise (e.g., receiving the service at a lower cost but with a greater chance to be criminally prosecuted). The decision to offer $\mathrm{B}_{\mathrm{C}}$ is also influenced by the prevailing cultural environment of the bribery players, as found out in separate laboratory observations by Alatas, et al. (2009), Cameron, et al. (2009), and Banuri, et al. (2010).

In reaction to Basu's argument for TAP in 2011, Abbink, et al. (2014) and Ryvin and Serra (2013) conducted separate studies to observe in laboratory settings the effectiveness of TAP in reducing harassment bribery. Notice that in TAP, only the public servant who demanded $\mathrm{B}_{\mathrm{H}}$ is punished while the citizen who (willingly or grudgingly) agreed to pay but complained is allowed to go free. The TAP argument was also given a thorough theoretical analysis by Dufwenberg and Spagnolo (2011). These studies found that the reduction to the incidence of harassment bribery is somewhat correlated to the inability of the public servant who demanded $\mathrm{B}_{\mathrm{H}}$ to legally retaliate against the citizen who participated in the bribery. This means that TAP will only be successful if there is enough evidence to prosecute the public servant for harassment bribery. However, if the evidence is not enough nor available, the public servant can retaliate by saying that the citizen was the one who offered $\mathrm{B}_{\mathrm{C}}$. Still, the cost of proving that harassment bribery occurred is shouldered by the one who complained, in this case the citizen. The same outcome is also true even if the criminal justice system implemented is TAPR.

\section{Effect of Multiple Servants}

One may argue that bribery happened because only one public servant has the monopoly of the public service needed. If the citizen does not have a choice of a public servant to receive the service from, then the citizen has no other way but to deal with the one who might demand for $\mathrm{B}_{\mathrm{H}}$. Because of this argument, Ryvin and Serra (2013) studied the extent to how having more than one public servant can reduce bribery, provided that the citizens have equal access to them and they provide the same service. The researchers found that the availability of multiple servants, who may or may not compete with each other, can expedite the reduction in incidence of bribery. However, the effect of multiple servants in reducing bribery incidents will be offset if the citizen will incur a high cost of finding SH among the multitude of public servants (GansMorse, et al., 2017; Ryvin and Serra, 2018).

\section{E. Propagation of Diseases and other Ideas}

The propagation of diseases that make people sick have long been studied and understood through a field of study called epidemiology. One of the most useful tools in studying, understanding, predicting, and prescribing control of diseases is mathematical modeling of disease propagation in a population (Frauenthal, 1980; Dicker, et al., 2006). Diseases are transmitted when a susceptible person $\mathrm{S}$ comes in contact with a disease-infected person I. When 
$\mathrm{S}$ is exposed to I for some time, $\mathrm{S}$ becomes infected too. However, when I gets well, she is considered as a recovered person R. Figure 1 visualizes the interaction between $\mathrm{S}, \mathrm{I}$ and $\mathrm{R}$. In the figure are three boxes with labels $\mathrm{S}$, I and R, each representing the type of person. The solid grey line with arrow that connects $\mathrm{S}$ to I means that a person of type $\mathrm{S}$ maybe transformed to a person of type I. Similarly, the solid grey line that connects from I to R means that the type I person may be transformed into a type $\mathrm{R}$ person. The grey circle labeled $\mathrm{R}_{\mathrm{SI}}$ on the grey line represents the rate of transformation from $S$ to $I$. The red dashed line with arrow that connects $S$ and the rate $R_{S I}$ means that $S$ had an influence to the rate of transformation $R_{S I}$. Similarly, the red dashed line connecting I and the rate $\mathrm{R}_{\mathrm{SI}}$ means that I also had an influence to the rate of transformation of $\mathrm{S}$ to I. The grey circle where the two red dashed lines meet also means that $\mathrm{S}$ and I interacted with one another that resulted into the transformation of $\mathrm{S}$ to I. This figure is used to develop the system of ODEs that mathematically describe these interactions.

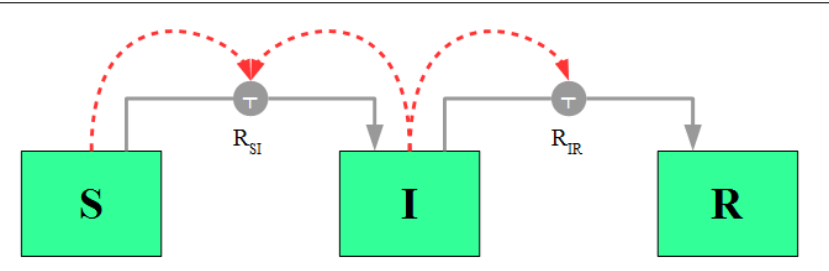

Figure 1. The interaction dynamics among different person types in an epidemiological event. The person types are $\mathrm{S}=$ Susceptibles, $\mathrm{I}=$ Infected, and $\mathrm{R}=$ Recovered.

The system of ODEs of the interaction depicted in Figure 1 is composed of the following equations as originally defined by Kermack and McKendrick (1927):

$$
\begin{aligned}
\mathrm{dS}(t) / \mathrm{d} t & =-\mathrm{R}_{\mathrm{SI}} \mathrm{S}(t) \mathrm{I}(t), \\
\mathrm{dI}(t) / \mathrm{d} t & =\mathrm{R}_{\mathrm{SI}} \mathrm{S}(t) \mathrm{I}(t)-\mathrm{R}_{\mathrm{IR}} \mathrm{I}(t), \text { and } \\
\mathrm{dR}(t) / \mathrm{d} t & =\mathrm{R}_{\mathrm{IR}} \mathrm{I}(t) .
\end{aligned}
$$

In these equations, $\mathrm{S}(t)$ is the number of persons of type $\mathrm{S}$ at time $t, \mathrm{I}(t)$ is the number of persons of type I at time $t$, and $\mathrm{R}(t)$ is the number of persons of type $\mathrm{R}$ at time $t$. The derivatives $\mathrm{dS}(t) / \mathrm{dt}$, $\mathrm{dI}(t) / \mathrm{d} t$, and $\mathrm{dR}(t) / \mathrm{d} t$ mean the instantaneous rate of change of the number of persons of type $\mathrm{S}$, type I, and type $\mathrm{R}$, respectively, at time $t$. Note that $0<\mathrm{R}_{\mathrm{SI}}<1$ and $0<\mathrm{R}_{\mathrm{IR}}<1$. Note further that the transformations in Figure 1 are consistently expressed mathematically as Equations [1] through [3]. For example, $\mathrm{S}$ in Figure 1 reduces by an amount $\mathrm{R}_{\mathrm{SI}}$ when $\mathrm{S}$ and I interact, which is what Equation [1] expresses. Similarly, the amount removed from $\mathrm{S}$ was added to I, which is what the first term of Equation [2] shows.

Mathematically, the system of ODEs involving equations [1], [2], and [3] requires solving for the functions $\mathrm{S}(t), \mathrm{I}(t)$, and $\mathrm{R}(t)$. Using analytical method, the system of ODEs has multiple solutions: A trivial solution and a non-trivial solution. The trivial solution depicts a scenario when there is no infection and therefore provides no useful information: $\mathrm{S}(t)$ is any non-negative constant, $\mathrm{I}(t)=0$, and $\mathrm{R}(t)=0$. The non-trivial one is difficult to compute manually which may require the need for a computerized algebra and calculus system to obtain the solution, which may be complex to present here. Instead, a numerical solution can approximate the non-trivial analytical solution via a 4th-order Runge-Kutta-Fehlberg method (Fehlberg, 1969): 


$$
\begin{aligned}
\mathrm{S}(t+\Delta t) & =\mathrm{S}(t)-\Delta t \mathrm{R}_{\mathrm{SI}} \mathrm{S}(t) \mathrm{I}(t), \\
\mathrm{I}(t+\Delta t) & =\mathrm{I}(t)+\Delta t\left(\mathrm{R}_{\mathrm{SI}} \mathrm{S}(t) \mathrm{I}(t)-\mathrm{R}_{\mathrm{IR}} \mathrm{I}(t)\right), \text { and } \\
\mathrm{R}(t+\Delta t) & =\mathrm{R}(t)+\Delta t \mathrm{R}_{\mathrm{IR}} \mathrm{I}(t) .
\end{aligned}
$$

Since a numerical solution is an approximation, $\Delta t$ must be optimally set as small as possible to reduce the error, but not too small that values computed within succeeding intervals become unusable for analysis. Equations [4], [5], and [6] respectively tell how the number of persons of type $\mathrm{S}, \mathrm{I}$, and $\mathrm{R}$ increase or decrease as affected by their interactions at each time step $\Delta t$ (see sample visualizations in Figure 2 for some values of $\mathrm{R}_{\mathrm{SI}}, \mathrm{R}_{\mathrm{IR}}$, and number of initial infected persons $\mathrm{I}(0)$ ). These mathematical tools can be used not only to model disease propagation but other disease-like phenomena that can propagate in a population like drug addiction (Pabico, 2017c), fake news (Pabico, 2018a), viral media stories (Smith?, 2014b) and even fictional phenomena like alien invasion (Pabico, 2017a), aswang (Pabico, 2017b), and zombies (Munz, et al., 2009; Smith?, 2014a). The same mathematical tools can also be used to model corruption propagation in the public service, treating corruption as a contagious disease.

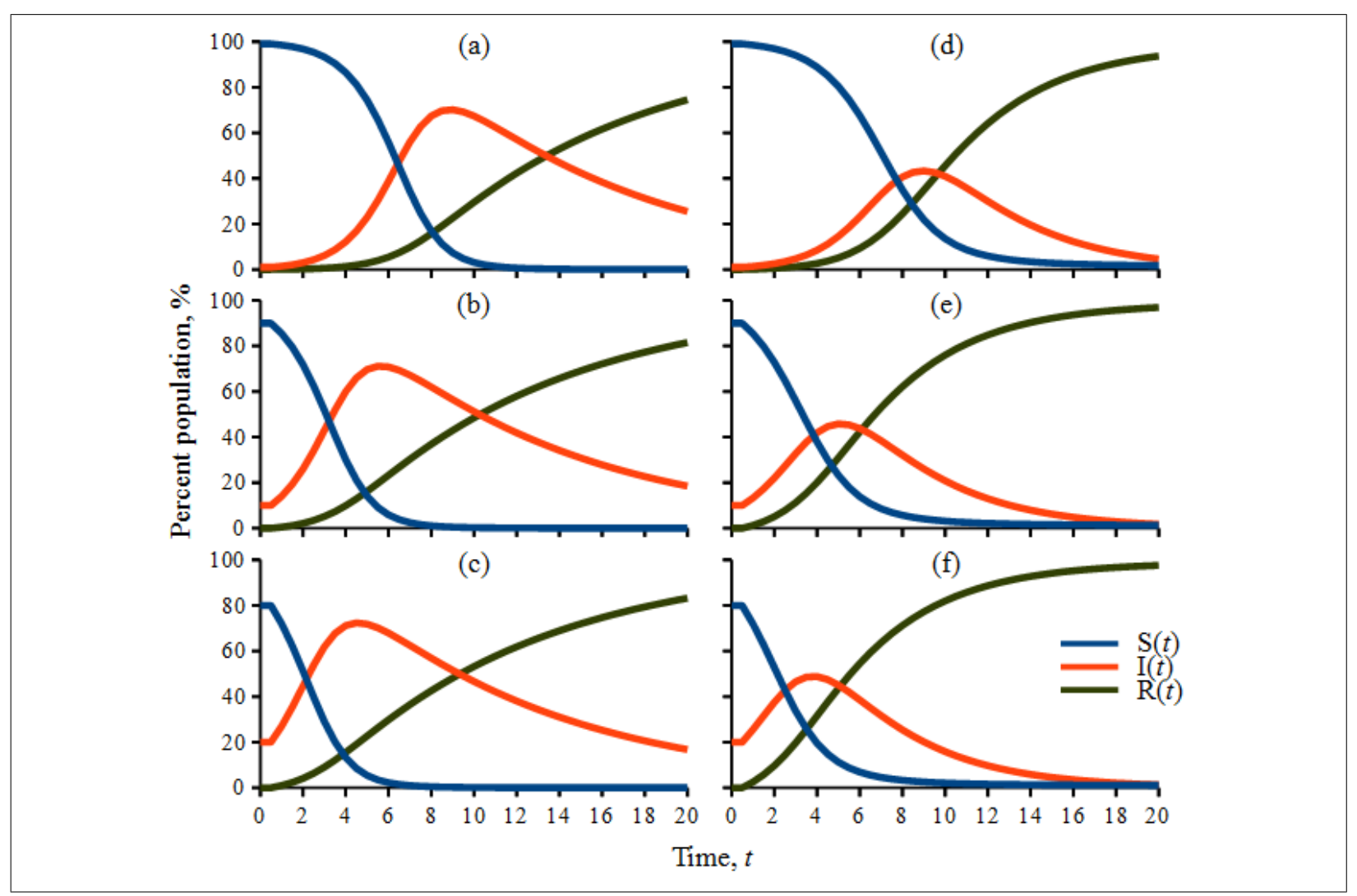

Figure 2. Sample different time evolutions representing combinations of scenarios of the epidemiological event depicted in Figure 1. For all graphs, $\mathrm{R}_{\mathrm{SI}}=0.01, \mathrm{R}(0)=0 \%$ and $\Delta t=0.5$. $\mathrm{R}_{\mathrm{IR}}=0.10$ For (a)-(c), while $\mathrm{R}_{\mathrm{IR}}=0.25$ for (d)-(f). $\mathrm{S}(0)=99$ and $\mathrm{I}(0)=1$ for both (a) and (d); $\mathrm{S}(0)=90$ and $\mathrm{I}(0)=10$ for (b) and (e); $\mathrm{S}(0)=80$ and $\mathrm{I}(0)=20$ for both (c) and (f). 


\section{MODELING THE PROPAGATION OF CORRUPTION}

The players in the bribery game often interact with one another and through that interaction, one can influence the other to either take the same beliefs as the former or take the opposite. For example, if a corrupt public servant interacts with an upright citizen, the public servant may be influenced to abandon her corrupt ways and become honest. In the same effect, the upright citizen may become a cooperator with the corrupt public servant and agree with her demands. In the following subsections, the dynamics of the following interactions are discussed: (a) Among public servants; (b) Among citizens; and (C) Between public servants and citizens.

\section{A. Interaction Dynamics Among Public Servants}

Figure 3 shows a visualization of the interactions among public servants. When SH and SC interact, $\mathrm{SH}$ may be negatively influenced by $\mathrm{SC}$ to become an $\mathrm{SX}$ by a rate $\mathrm{R}_{\mathrm{HX}}$. However, the effect of the interaction may be mutual that $\mathrm{SC}$ may be positively influenced by $\mathrm{SH}$ to become an $\mathrm{SX}$ by a rate $1-\mathrm{R}_{\mathrm{HX}}$. When $\mathrm{SH}$ and $\mathrm{SX}$ interact, $\mathrm{SH}$ may have a stronger influence to $\mathrm{SX}$ that it may transform her back to being $\mathrm{SH}$ by a rate $\mathrm{R}_{\mathrm{XH}}$. In the same manner, when $\mathrm{SX}$ and $\mathrm{SC}$ interact, SC may have a stronger negative influence to SX that it may transform her to becoming a full $\mathrm{SC}$ by a rate $\mathrm{R}_{\mathrm{xc}}$. Note here that $\mathrm{SX}$ is a person on a crossroad, so she can easily be swayed to go their side by either SH or SC. The interaction of SX with SD has the same positive effect as her interaction with $\mathrm{SH}$, but with a rate $\mathrm{R}_{\mathrm{XHD}}$. SD has a positive enfluence with $\mathrm{SC}$ as their interaction will result into the transformation of SC to SX by a rate $\mathrm{R}_{\mathrm{CXD}}$. All rates of transformation are defined in Table 1.

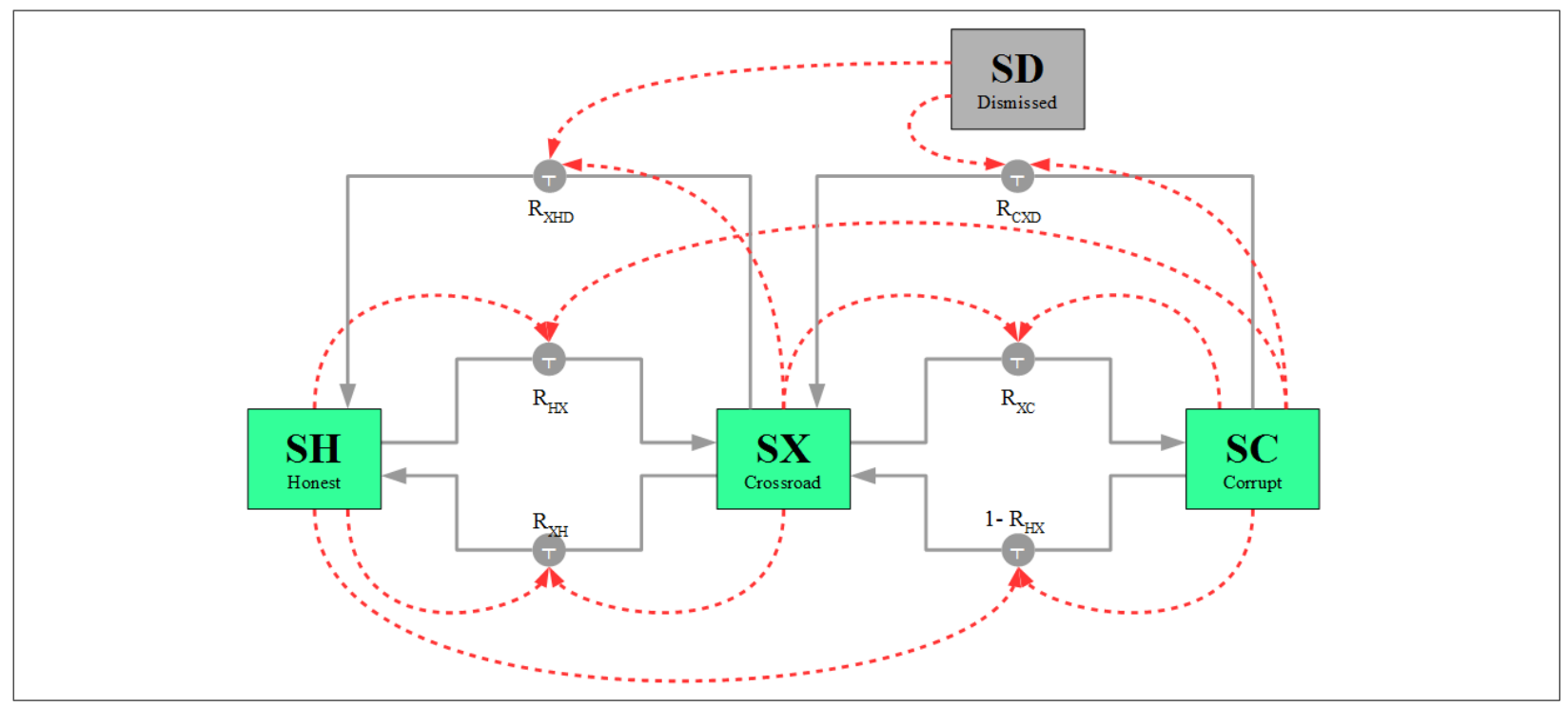

Figure 3. The interaction dynamics among public servants: $\mathrm{SH}=$ honest, $\mathrm{SX}=$ on a crossroad; $\mathrm{SC}=\mathrm{corrupt}$, and $\mathrm{SD}=$ dismissed. 
Table 1. The rates of transformation when public servants interact with one another.

\begin{tabular}{cl}
\hline Rate & Definition \\
\hline $\mathrm{R}_{\mathrm{CXD}}$ & The rate by which SC transforms to SX due to the influence of SD \\
$\mathrm{R}_{\mathrm{HX}}$ & The rate by which SH transforms to SX \\
$\mathrm{R}_{\mathrm{XC}}$ & The rate by which SX transforms to SC \\
$\mathrm{R}_{\mathrm{XH}}$ & The rate by which SX transforms to SH \\
$\mathrm{R}_{\mathrm{XHD}}$ & The rate by which SX transforms to SH due to the influence of SD \\
\hline \hline
\end{tabular}

The system of ODEs that describe the interaction dynamics of the public servants can be derived from Figure 3 using the rates in Table 1:

$$
\begin{aligned}
\mathrm{dSH}_{\mathrm{S}}(t) / \mathrm{d} t= & -\mathrm{R}_{\mathrm{HX}} \mathrm{SH}(t) \mathrm{SC}(t)+\mathrm{R}_{\mathrm{XH}} \mathrm{SH}(t) \mathrm{SX}(t)+\mathrm{R}_{\mathrm{XHD}} \mathrm{SD}(t) \mathrm{SX}(t), \\
\mathrm{dSX}_{\mathrm{S}}(t) / \mathrm{d} t= & \mathrm{R}_{\mathrm{HX}} \mathrm{SH}(t) \mathrm{SC}(t)-\mathrm{R}_{\mathrm{XH}} \mathrm{SH}(t) \mathrm{SX}(t)-\mathrm{R}_{\mathrm{XHD}} \mathrm{SD}(t) \operatorname{SX}(t) \\
& -\mathrm{R}_{\mathrm{XC}} \mathrm{SX}(t) \mathrm{SC}(t)+\left(1-\mathrm{R}_{\mathrm{HX}}\right) \mathrm{SH}(t) \operatorname{SC}(t)+\mathrm{R}_{\mathrm{CXD}} \mathrm{SD}(t) \mathrm{SC}(t), \\
\mathrm{dSC}_{\mathrm{S}}(t) / \mathrm{d} t= & \mathrm{R}_{\mathrm{XC}} \mathrm{SX}(t) \mathrm{SC}(t)-\left(1-\mathrm{R}_{\mathrm{HX}}\right) \mathrm{SH}(t) \mathrm{SC}(t)-\mathrm{R}_{\mathrm{CXD}} \operatorname{SD}(t) \operatorname{SC}(t) .
\end{aligned}
$$

The functions $\mathrm{SH}(t), \operatorname{SX}(t)$, and $\mathrm{SC}(t)$ in the right-hand side of the equations are the number of public servants who are honest, on a crossroads, and corrupt at time $t$, respectively. The instantaneous rates of change $\mathrm{dSH}_{\mathrm{S}}(t) / \mathrm{d} t, \mathrm{dSX}_{\mathrm{S}}(t) / \mathrm{d} t$, and $\mathrm{dSC}_{\mathrm{S}}(t) / \mathrm{d} t$ are the respective derivatives of the functions with respect to $t$, but only within the interactions of the public servants. The other factors due the public servants' interaction with the citizen will be added later. Notice further that $\operatorname{SD}(t)$ will be defined later in Section $C$ where the public servants interact with the citizens.

\section{B. Interaction Dynamics Among Citizens}

The dynamics of interaction among citizens is depicted in Figure 4. When CU and CA interact, the positive enfluence of $\mathrm{CU}$ may encourage $\mathrm{CA}$ to transform back to $\mathrm{CU}$ at a rate of $\mathrm{R}_{\mathrm{AUU}}$. The same positive effect will happen if $\mathrm{CA}$ interacts with $\mathrm{CW}$, but with a rate of $\mathrm{R}_{\mathrm{AUw}}$. $\mathrm{CC}$ could be transformed by a rate of $\mathrm{R}_{\mathrm{CA}}$ to being $\mathrm{CA}$ when $\mathrm{CU}$ and $\mathrm{CC}$ interact. $\mathrm{CC}$ might have a stronger enfluence over $\mathrm{CA}$ because their interaction may cause $\mathrm{CA}$ to transform to $\mathrm{CC}$ at a rate $\mathrm{R}_{\mathrm{AC}}$. When $\mathrm{CC}$ and $\mathrm{CW}$ interact, $\mathrm{CC}$ might be convinced that being $\mathrm{CW}$ is a much better state so she will be transformed into that via a rate of $\mathrm{R}_{\mathrm{Cw}}$. Finally, $\mathrm{CW}$ may be transformed into $\mathrm{CU}$ if they ever interact with a rate of $\mathrm{R}_{\mathrm{wu}}$. The rates of interaction among citizens are described in Table 2.

The interaction dynamics that can be derived from Figure 4 using the rates in Table 2 are as follows:

$$
\begin{aligned}
\mathrm{dCU}_{\mathrm{C}}(t) / \mathrm{d} t= & \mathrm{R}_{\mathrm{WU}} \mathrm{CW}(t) \mathrm{CU}(t)+\mathrm{R}_{\mathrm{AUU}} \mathrm{CU}(t) \mathrm{CA}(t)+\mathrm{R}_{\mathrm{AUw}} \mathrm{CA}(t) \mathrm{CW}(t), \\
\mathrm{dCA}_{\mathrm{C}}(t) / \mathrm{d} t= & \mathrm{R}_{\mathrm{CA}} \mathrm{CU}(t) \mathrm{CC}(t)-\mathrm{R}_{\mathrm{AUU}} \mathrm{CU}(t) \mathrm{CA}(t) \\
& -\mathrm{R}_{\mathrm{AUW}} \mathrm{CA}(t) \mathrm{CW}(t)-\mathrm{R}_{\mathrm{AC}} \mathrm{CA}(t) \mathrm{CC}(t), \\
\mathrm{dCC}_{\mathrm{C}}(t) / \mathrm{d} t= & \mathrm{R}_{\mathrm{AC}} \mathrm{CA}(t) \mathrm{CC}(t)-\mathrm{R}_{\mathrm{CA}} \mathrm{CU}(t) \mathrm{CC}(t)-\mathrm{R}_{\mathrm{CW}} \mathrm{CC}(t) \mathrm{CW}(t), \text { and } \\
\mathrm{dCW}_{\mathrm{C}}(t) / \mathrm{d} t= & \mathrm{R}_{\mathrm{CW}} \mathrm{CC}(t) \mathrm{CW}(t)-\mathrm{R}_{\mathrm{WU}} \mathrm{CW}(t) \mathrm{CU}(t) .
\end{aligned}
$$




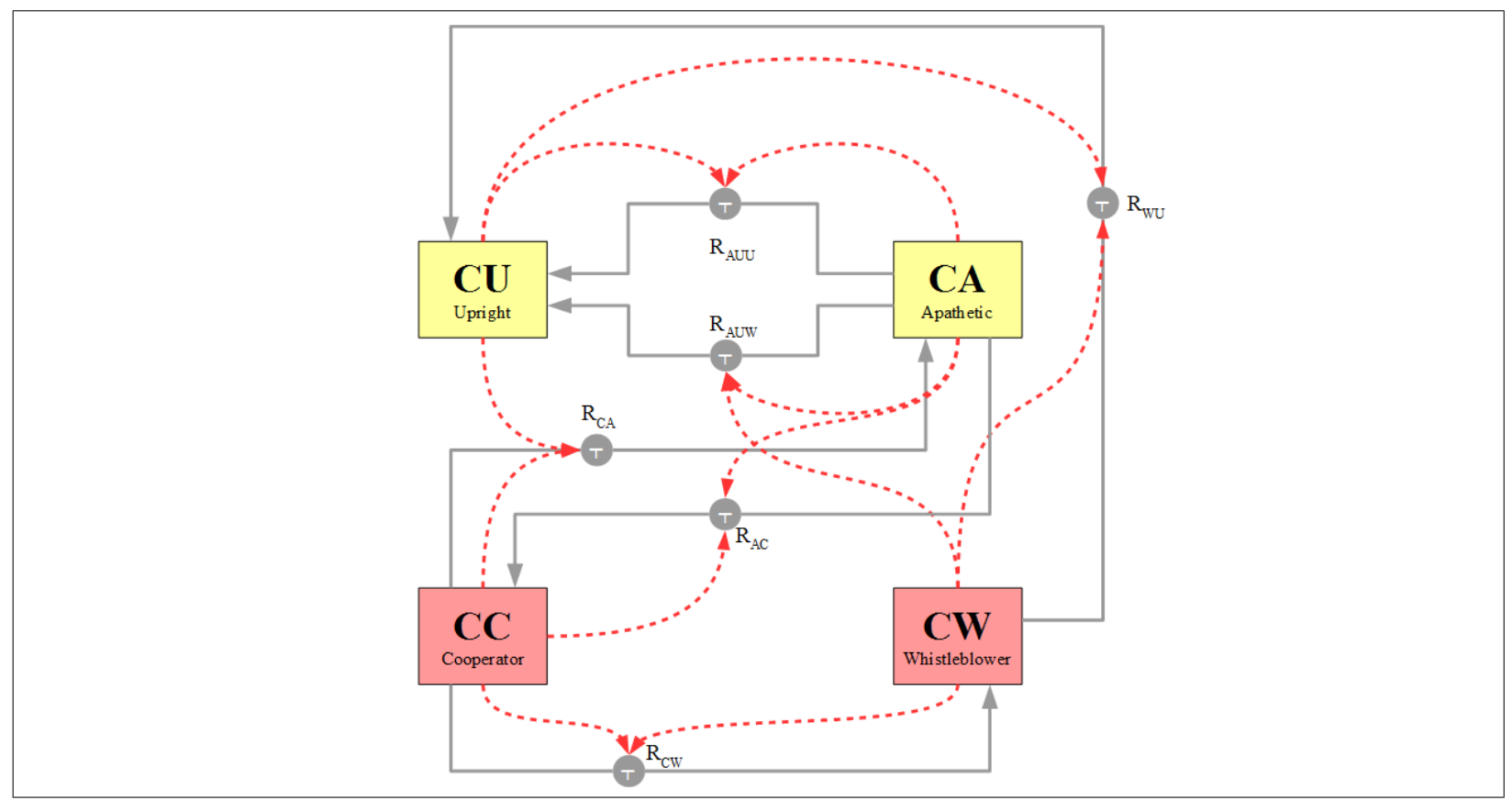

Figure 4. The interaction dynamics among citizens: $\mathrm{CU}=$ upright, $\mathrm{CA}=$ apathetic; $\mathrm{CC}=$ cooperator, and $\mathrm{CW}=$ whistleblower.

Table 2. The rates of transformation when citizens interact with one another.

\begin{tabular}{ll}
\hline \hline Rate & Definition \\
\hline $\mathrm{R}_{\mathrm{AC}}$ & The rate by which CA transforms to CC \\
$\mathrm{R}_{\mathrm{AUU}}$ & The rate by which CA transforms to CU due to CU \\
$\mathrm{R}_{\mathrm{AUW}}$ & The rate by which CA transforms to CU due to CW \\
$\mathrm{R}_{\mathrm{CA}}$ & The rate by which CC transforms to CA \\
$\mathrm{R}_{\mathrm{CW}}$ & The rate by which CC transforms to CW \\
$\mathrm{R}_{\mathrm{WU}}$ & The rate by which CW transforms to CU \\
\hline \hline
\end{tabular}

The functions $\mathrm{CU}(t), \mathrm{CA}(t), \mathrm{CC}(t)$ and $\mathrm{CW}(t)$ found in the right-hand side of the equations are the respective number of citizens who are upright, apathetic, cooperator, and whistleblower. The derivatives $\mathrm{dCU}_{\mathrm{C}}(t) / \mathrm{d} t, \mathrm{dCA}_{\mathrm{C}}(t) / \mathrm{d} t, \mathrm{dCC}_{\mathrm{C}}(t) / \mathrm{d} t$, and $\mathrm{dCW}_{\mathrm{C}}(t) / \mathrm{d} t$ are the partial rate of change of the functions as affected by the interaction among citizens only.

\section{Interaction Dynamics between Public Servants and Citizens}

Figure 5 visualizes the interaction dynamics between the public servant and the citizens. Because a CU will always complain when demanded with $\mathrm{B}_{\mathrm{H}}, \mathrm{SX}$ will be transformed into SD when a $\mathrm{CU}$ interacts with SX at a rate $\mathrm{R}_{\mathrm{XDU}}$. Similarly, $\mathrm{SC}$ will be transformed into SD when a CU interact with an $\mathrm{SC}$ at a rate $\mathrm{R}_{\mathrm{CDU}}$. The effect of $\mathrm{CU}$ to both $\mathrm{SX}$ and $\mathrm{SC}$ are devastatingly negative for them, which is also the same effect when they interact with CW: SX will be transformed into SD 
when a CW interacts with SX at a rate $\mathrm{R}_{\mathrm{XDw}}$, while $\mathrm{SC}$ will be transformed into $\mathrm{SD}$ when she interacts with a $\mathrm{CW}$ at a rate $\mathrm{R}_{\mathrm{CDW}}$. When a CA interacts with an SX, the SX may have a change

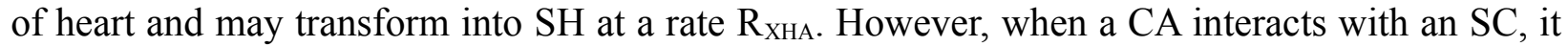
is the CA that will transform positively into being $\mathrm{CU}$ at a rate $\mathrm{R}_{\mathrm{AUC}}$.

The effect of SC to $\mathrm{CA}$ is not at all positive, CA may transform instead into being $\mathrm{CC}$ when interacting with $\mathrm{SC}$ at a rate $\mathrm{R}_{\mathrm{ACC}}$. Because a $\mathrm{CC}$ will cooperate all the time and will not complain, she will have a negative enfluence to a SX such that their interaction will cause SX to transform into $\mathrm{SC}$ at a rate $\mathrm{R}_{\mathrm{XCC}}$. When a $\mathrm{CC}$ interacts with a $\mathrm{SC}$, the $\mathrm{CC}$ may transform into being a $\mathrm{CW}$ at a rate $\mathrm{R}_{\mathrm{CWC}}$. The rates as discussed here are summarized in Table 3.

Below are the equations that can be derived from Figure 5 using the rates in Table 3:

$$
\begin{aligned}
\mathrm{dCU}_{\mathrm{X}}(t) / \mathrm{d} t & =\mathrm{R}_{\mathrm{AUC}} \mathrm{CA}(t) \mathrm{SC}(t), \\
\mathrm{dCA}_{\mathrm{X}}(t) / \mathrm{d} t= & -\mathrm{R}_{\mathrm{AUC}} \mathrm{CA}(t) \mathrm{SC}(t)-\mathrm{R}_{\mathrm{ACC}} \mathrm{CA}(t) \mathrm{SC}(t), \\
\mathrm{dCC}_{\mathrm{X}}(t) / \mathrm{d} t= & \mathrm{R}_{\mathrm{ACC}} \mathrm{CA}(t) \mathrm{SC}(t)-\mathrm{R}_{\mathrm{CWC}} \mathrm{CC}(t) \mathrm{SC}(t), \\
\mathrm{dCW}_{\mathrm{X}}(t) / \mathrm{d} t= & \mathrm{R}_{\mathrm{CWC}} \mathrm{CC}(t) \mathrm{SC}(t), \\
\mathrm{dSH}_{\mathrm{X}}(t) / \mathrm{d} t= & \mathrm{R}_{\mathrm{XHA}} \mathrm{CA}(t) \mathrm{SX}(t), \\
\mathrm{dSX}(t) / \mathrm{d} t= & -\mathrm{R}_{\mathrm{XHA}} \mathrm{CA}(t) \mathrm{SX}(t)-\mathrm{R}_{\mathrm{XDU}} \mathrm{CU}(t) \mathrm{SX}(t) \\
& -\mathrm{R}_{\mathrm{XDW}} \mathrm{CW}(t) \mathrm{SX}(t)-\mathrm{R}_{\mathrm{XCC}} \mathrm{CC}(t) \mathrm{SX}(t), \\
\mathrm{dSC}_{\mathrm{X}}(t) / \mathrm{d} t= & \mathrm{R}_{\mathrm{XCC}} \mathrm{CC}(t) \mathrm{SX}(t)-\mathrm{R}_{\mathrm{CDU}} \mathrm{CU}(t) \mathrm{SC}(t)-\mathrm{R}_{\mathrm{CDW}} \mathrm{CW}(t) \mathrm{SC}(t), \text { and }[20] \\
\mathrm{dSD}_{\mathrm{X}}(t) / \mathrm{d} t= & \mathrm{R}_{\mathrm{XDU}} \mathrm{CU}(t) \mathrm{SX}(t)+\mathrm{R}_{\mathrm{XDW}} \mathrm{CW}(\mathrm{t}) \operatorname{SX}(\mathrm{t}) \\
& +\mathrm{R}_{\mathrm{CDU}} \mathrm{CU}(t) \mathrm{SC}(t)+\mathrm{R}_{\mathrm{CDW}} \mathrm{CW}(t) \mathrm{SC}(t) .
\end{aligned}
$$

The derivatives defined in equations [14] through [21] are due to the interaction between the public servants and the citizens only.

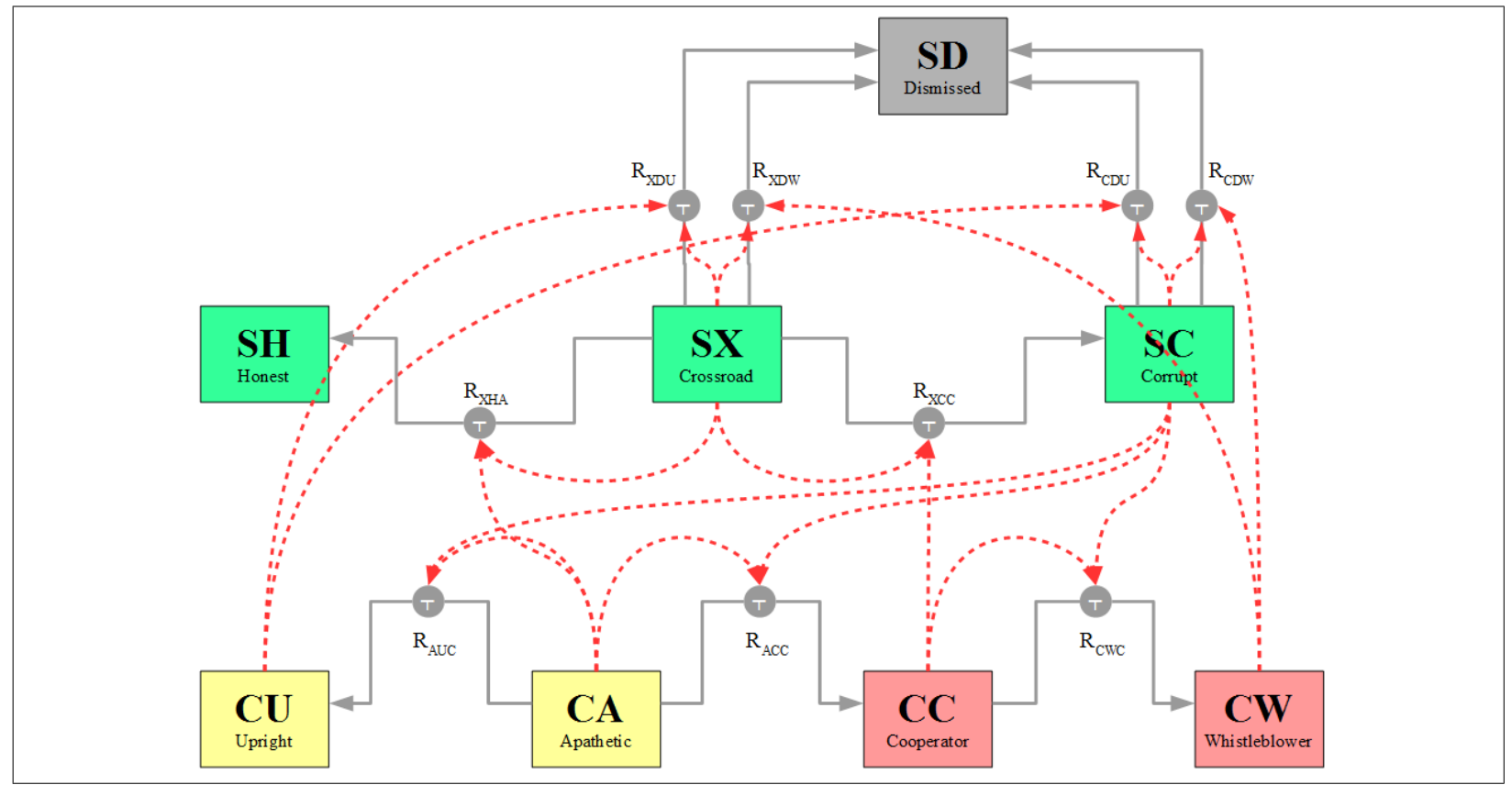

Figure 5. The interaction dynamics between the public servants and the citizens. 
Table 3. The rates of transformation when public servants and citizens interact with one another.

\begin{tabular}{cl}
\hline \hline Rate & Definition \\
\hline $\mathrm{R}_{\mathrm{ACC}}$ & The rate by which CA transforms to CC due to SC \\
$\mathrm{R}_{\mathrm{AUC}}$ & The rate by which CA transforms to CU due to SC \\
$\mathrm{R}_{\mathrm{CDU}}$ & The rate by which SC transforms to SD due to CU \\
$\mathrm{R}_{\mathrm{CDW}}$ & The rate by which SC transforms to SD due to CW \\
$\mathrm{R}_{\mathrm{CWC}}$ & The rate by which CC transforms to CW due to SC \\
$\mathrm{R}_{\mathrm{XCC}}$ & The rate by which SX transforms to SC due to CC \\
$\mathrm{R}_{\mathrm{XHA}}$ & The rate by which $\mathrm{SX}$ transforms to SH due to CA \\
$\mathrm{R}_{\mathrm{XDU}}$ & The rate by which SX transforms to SD due to CU \\
$\mathrm{R}_{\mathrm{XDW}}$ & The rate by which SX transforms to SD due to CW \\
\hline \hline
\end{tabular}

\section{System of ODEs}

Combining the partial equations from equations [7] through [21], the final system of ODEs is given as:

$$
\begin{aligned}
\mathrm{dSH}(t) / \mathrm{d} t & =\left(\operatorname{dSH}_{\mathrm{S}}(t) / \mathrm{d} t+\mathrm{dSH}_{\mathrm{X}}(t) / \mathrm{d} t\right) / N, \\
\mathrm{dSX}(t) / \mathrm{d} t & =\left(\mathrm{dSX}_{\mathrm{S}}(t) / \mathrm{d} t+\mathrm{dSX}_{\mathrm{X}}(t) / \mathrm{d} t\right) / N, \\
\mathrm{dSC}(t) / \mathrm{d} t & =\left(\mathrm{dSC}_{\mathrm{S}}(t) / \mathrm{d} t+\mathrm{dSC}_{\mathrm{X}}(t) / \mathrm{d} t\right) / N, \\
\mathrm{dSD}(t) / \mathrm{d} t & =\left(\operatorname{dSD}_{\mathrm{X}}(t) / \mathrm{d} t\right) / N, \\
\mathrm{dCU}(t) / \mathrm{d} t & =\left(\operatorname{dCU}_{\mathrm{C}}(t) / \mathrm{d} t+\mathrm{dCU}_{\mathrm{X}}(t) / \mathrm{d} t\right) / N, \\
\mathrm{dCA}(t) / \mathrm{d} t & =\left(\operatorname{dCA}_{\mathrm{C}}(t) / \mathrm{d} t+\mathrm{dCA}_{\mathrm{X}}(t) / \mathrm{d} t\right) / N, \\
\mathrm{dCC}(t) / \mathrm{d} t & =\left(\mathrm{dCC}_{\mathrm{C}}(t) / \mathrm{d} t+\mathrm{dCC}_{\mathrm{X}}(t) / \mathrm{d} t\right) / N, \text { and } \\
\mathrm{dCW}(t) / \mathrm{d} t & =\left(\mathrm{dCW}_{\mathrm{C}}(t) / \mathrm{d} t+\mathrm{dCW}_{\mathrm{X}}(t) / \mathrm{d} t\right) / N .
\end{aligned}
$$

Notice that the equations above are normalized with a quantity equal to the total population $N=$ $\mathrm{SH}(t)+\mathrm{SX}(t)+\mathrm{SC}(t)+\mathrm{SD}(t)+\mathrm{CU}(t)+\mathrm{CA}(t)+\mathrm{CC}(t)+\mathrm{CW}(t)$. Notice further that in equation [25], $\mathrm{dSD}(t) / \mathrm{d} t$ is just a function of $\mathrm{dSD}_{\mathrm{X}}(t) / \mathrm{d} t$ because no $\mathrm{dSD}_{\mathrm{C}}(t) / \mathrm{d} t$ component was derived in Section A. Remember that all derivatives with a subscript $\mathrm{S}$ were derived in Section A, those with subscript $\mathrm{C}$ were derived in Section B, while all with subscript $\mathrm{X}$ were derived in Section $\mathrm{C}$. The analytical solution to an 8-equation system of ODEs may be difficult to find even with the aid of a modern computerized algebra and calculus system. In this paper, the above system was transated into its numerical counterpart (henceforth will now be called as the model) following the Runge-Kutta-Fehlberg procedure (Fehlberg, 1969).

\section{RESULTS}

Although the model described by Equations [22] through [29] can be used to simulate various scenarios composed of a combination of public policy and culture, the results that are discussed in this section are hypothetical involving utopian communities (Subsection A), and the effect of perturbing the utopian community with an infection of corruption (Subsection B). Using the 
model, answers to some questions were looked into such as the sole effects of apathetic (Subsection C), cooperating, and whistleblowing citizenry (Subsection D) to the transformations in the public service if the public service is composed of 50\% honest and $50 \%$ corrupt servants. For all the model runs, the rates used are 0.5 . The rates mean that when two types interact, half of those which interacted will be transformed while half will remain in their type. The choice of 0.5 is arbitrary and does not reflect any public service policies nor cultural settings. Thus, the use of dimensionless time $t$ in the discussions that follow was made intentional. Depending on the context that may apply, one can just subtitute their own unit of time (days, months, years, decades, etc.).

\section{A. The Utopian Equilibrium and Model Stability}

One trivial solution to the model is when all public servants are honest and all citizens are upright all the time. This utopian community is when $\mathrm{SH}(0)$ and $\mathrm{CU}(0)$ are both at $100 \%$, while $\mathrm{SX}(0), \mathrm{SC}(0), \mathrm{SD}(0), \mathrm{CA}(0), \mathrm{CC}(0)$, and $\mathrm{CW}(0)$ are all $0 \%$. Since there are no corrupted public servant nor cooperating citizen that exist, then no "infection" can occur in the population, and therefore the honest public servant stays honest, and the upright citizen stays upright. Mathematically, the model is said to be in equilibrium when all functions stay constant for some $t>0$. This means that $\mathrm{SH}(t)=100 \%, \mathrm{SX}(t)=0 \%, \mathrm{SC}(t)=0 \%, \mathrm{SD}(t)=0 \%, \mathrm{CU}(t)=100 \%, \mathrm{CA}(t)$ $=0 \%, \mathrm{CC}(t)=0 \%$, and $\mathrm{CW}(t)=0 \%$.

Will the utopian government still persist even if $1 \%$ of the citizens become a cooperator? The answer to this question is yes. That small portion of $\mathrm{CC}$ will have no effect on the honest public servant because there is no one to cooperate with after all. Initially, portions of that $\mathrm{CC}$ were transformed into $\mathrm{CA}$ such that there were instances that both $\mathrm{CA}$ and $\mathrm{CC}$ existed in the population (Figure 6b). In the long run, however, both $\mathrm{CC}$ and $\mathrm{CA}$ were transformed to $\mathrm{CU}$ (Figure 6a) and the whole community returned back to the utopian equilibrium. Thus, a utopian public service can heal an "infected" citizenry. The small perturbation that was introduced to the equilibrium resulted into a slight change in the evolution of some classes, but they eventually returned back to the same equilibrium. This happens because the model is stable (Liu and Zeng, 2017). The stability analysis of the model is presented in another paper (Pabico, 2018b).
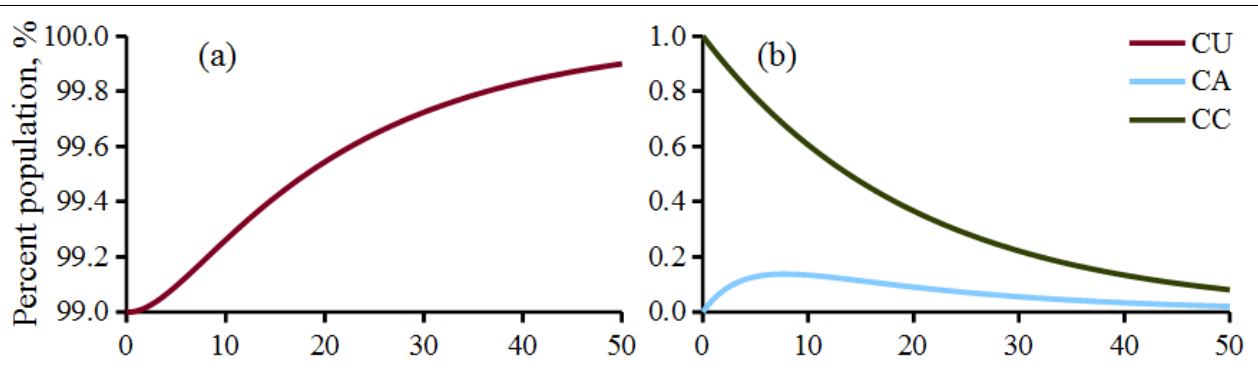

Time, $t$

Figure 6. The effect of perturbing the utopian equilibrium by introducing a small $\mathrm{CC}(0)=1 \%$ change to the population of citizens. 


\section{B. Effects of a Few Rotten Bananas}

What is the effect of "seeding" the utopian scenario with a few "infected" public servants? Will the public service be able to heal itself if the citizens they serve stay upright? To answer these questions, the model was started with $\mathrm{SH}(0)=99 \%, \mathrm{SX}(0)=0 \%, \mathrm{SC}(0)=1 \%, \mathrm{SD}(0)=0 \%$, $\mathrm{CU}(0)=100 \%, \mathrm{CA}(0)=0 \%, \mathrm{CC}(0)=0 \%, \mathrm{CW}(0)=0 \%$, and all rates are kept to 0.5 . This means that among the public servants, $99 \%$ are honest and only one percent is corrupt, while the citizens they serve are all upright. Figure 7 shows the time evolution of the changes in $\mathrm{SX}(t)$, $\mathrm{SC}(t)$, and $\mathrm{SD}(t)$ that happened within such a scenario.

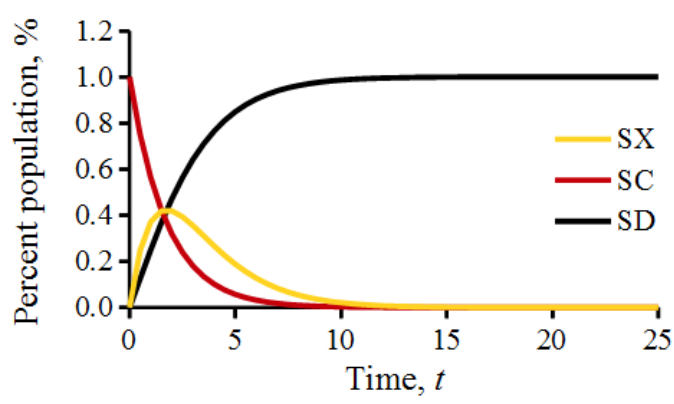

Figure 7. The transformation of the lone SC into SD when the public service started with 99 honest public servants, one corrupt public servant, and 100 upright citizens.

In the figure, it can be seen that the SC (red line) transitions into SD (black line) just after about $t$ $=7.5$. Notice that the percentages of $\mathrm{SX}(t), \mathrm{SC}(t)$, and $\mathrm{SD}(t)$ are practically equal to about $0.4 \%$ at $t=1.5$. This means that parts of the SCs have already transitioned to SX or SD, while parts stayed being SC. However, since both SX and SC were interacting with CUs all the time, after about six time steps $t$, they were transformed into SD. Notice that after $t=7.5$, the public service was able to "heal" itself from corruption, and the public service goes back to being utopian, albeit with one percent less public servants which are now dismissed for all $t>7.5$.

The next question to ask is how long will it take to heal the public service if it started with a higher percentages of SC? To answer this question, several runs of the model were conducted taking in initial conditions as above but with differences as follows: (1) $\mathrm{SH}(0)=95 \%, \mathrm{SC}(0)=$ $5 \%$; (2) $\mathrm{SH}(0)=90 \%, \mathrm{SC}(0)=10 \%$; (3) $\mathrm{SH}(0)=75 \%, \mathrm{SC}(0)=25 \%$; (4) $\mathrm{SH}(0)=50 \%, \mathrm{SC}(0)=$ $50 \%$; and $(5) \mathrm{SH}(0)=25 \%, \mathrm{SC}(0)=75 \%$.

Figure 8 shows the evolution of $\mathrm{SC}(t)$ and $\mathrm{SD}(t)$ as $t$ increases. The time transformation for $\mathrm{SC}$ is shown in Figure 8(a), while that for SD is in Figure 8(b). Notice that for all scenarios, the public service was able to heal itself and get rid of the seeded SC by transforming all of them to SD, but at longer time as $\mathrm{SC}(0)$ increases. When all the citizens are upright, the corruption in the public service can be removed. 


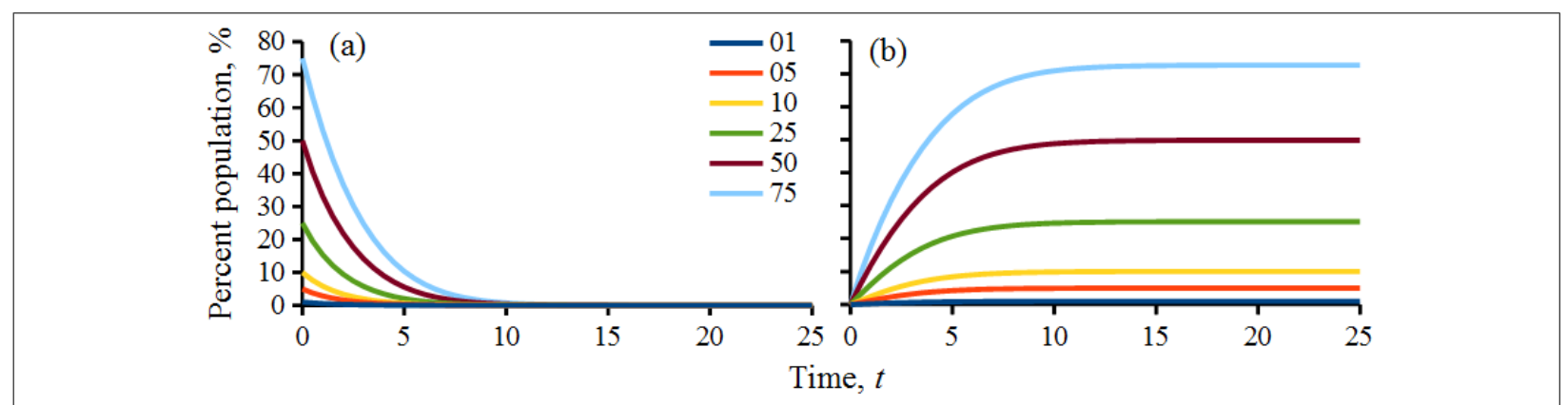

Figure 8. The transformation of a few SCs into SDs when the public service has upright citizens: (a) The time evolution of SCs; and (b) The time evolution of SDs.

\section{The Contribution of "I Don't Care"}

Apathy is doing nothing when faced with corruption in the public service. This is what CA does even though she does not avail of the service when demanded to pay for $\mathrm{B}_{\mathrm{H}}$. Her attitude somehow allows the public servant to go unpunished, which indirectly encourages corruption to continue on. It has been shown above that when all citizens availing public service is upright, no matter the number of corrupted public servants, the service always heals by getting rid of the corrupted. In this section, the effects of CA to the evolution of corruption are investigated. Using the same rates as above, the model was seeded with $\mathrm{SH}(0)=50 \%$ and $\mathrm{SC}(0)=50 \%$. This means that, while half of the public servants are honest, half are corrupted from the start. The initial values for $\mathrm{CU}(0), \mathrm{CC}(0)$, and $\mathrm{CW}(0)$ were kept constant at zero percent, while that of the apathetic citizens $\mathrm{CA}(0)$ was at $100 \%$. The results of the time evolution for both public servants and citizens are shown in Figure 9.

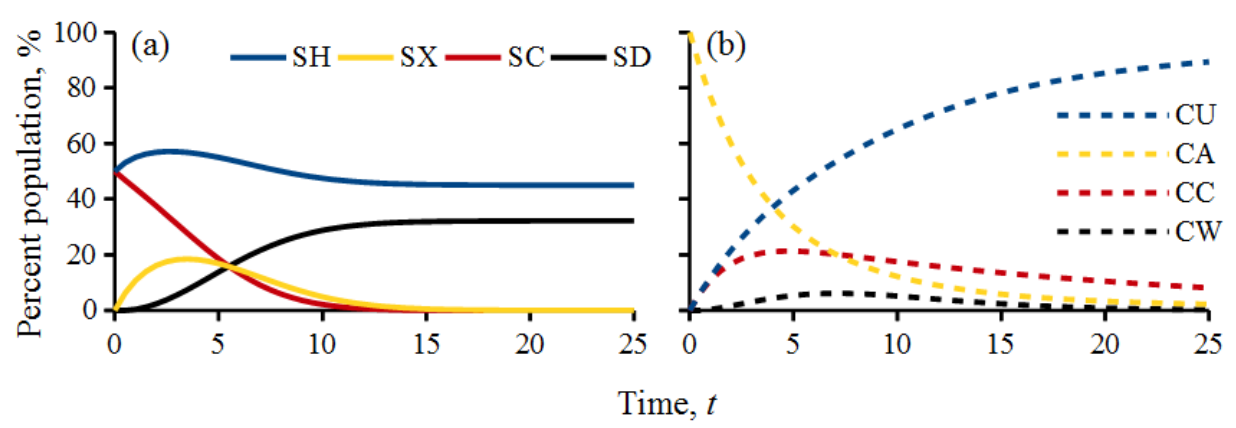

Figure 9. The effect of apathetic citizens on: (a) The time evolution among public servants; and (b) The time evolution among citizens.

Out of all the CAs that initially started, CU, CC, and CW came out (Figure 9b). This means that apathy can result to obtaining upright citizens, collaborating citizens, and some whistleblowers. As a result, parts of SC transformed into SX, with the percentage of SH spiking to about $60 \%$ at $t$ between 0 and 7.5 but eventually plateaued into equilibrium at about $47 \%$ just after $t=15$ 
(Figure 9a). Because CU and CW became present, some of the SX and SC were transformed into $\mathrm{SD}$, the percentage of which plateaued to about $30 \%$ starting at $t=15$. Notice that the rate by which CA transformed into CU in Figure $9 \mathrm{~b}$ is due to the choice of transformation rates that the simulation was ran with.

\section{Cooperating and Whistleblowing}

What will now happen if instead the citizenry is composed of $100 \%$ cooperators? The model simulated the same scenario as Section $\mathrm{C}$ above, but instead the citizenry was seeded with $\mathrm{CC}(0)$ $=100 \%$. The results are visualized in Figure 10 where it shows the time evolution of the public servants and the citizens. Notice that the transformations in the public service shown in Figure 10a have the same patterns as that in Figure 9a. The slight difference is that the SH plateaued to about 55\%, while the SD plateaued to just about 20\%. No CU nor CA were transformed from $\mathrm{CC}$, but instead they were all transformed to $\mathrm{CW}$ after some longer time $t>25$ (Figure 10b). Although apathetic citizenry transformed CAs into CUs, it resulted into less SHs but more SDs, as shown in Figure 9. However, cooperating citizenry transformed CCs into CWs, but resulted into more SHs and less SDs.

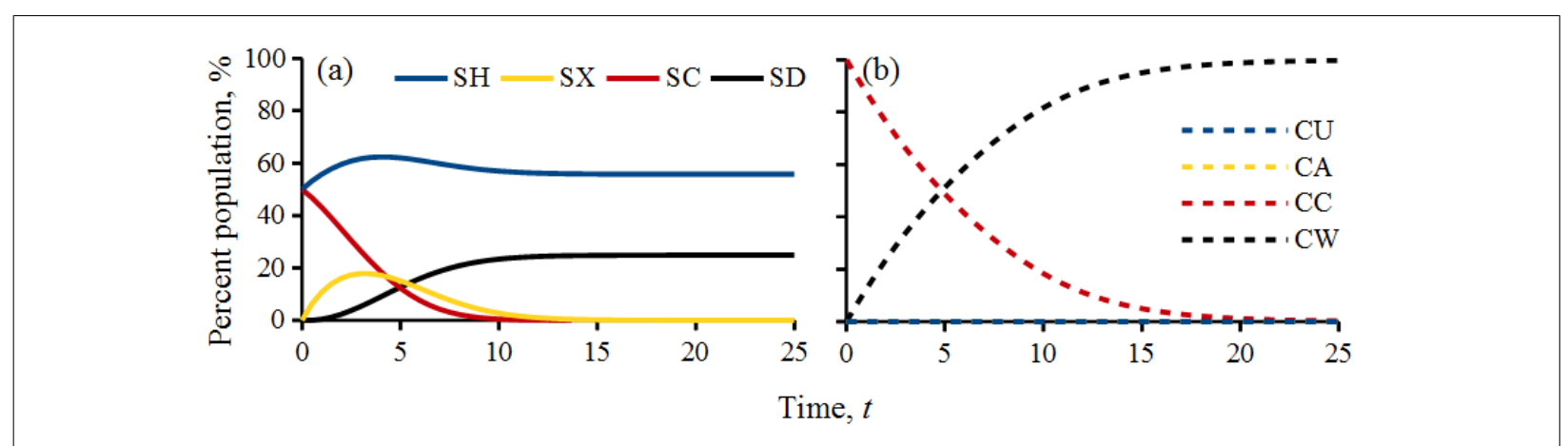

Figure 10. The effect of cooperating citizens on: (a) The time evolution among public servants; and (b) The time evolution among citizens.

It is now interesting to see the effect of citizenry composed of $100 \%$ whistle blowers to $50 \%$ honest and 50\% corrupt public service. The model simulated the same scenario as above, but instead seeded with $\mathrm{CW}(0)=100 \%$ while all citizen types started with zero percent. Here, all whistleblowers remain whistleblowers throughout (and therefore they were not transformed into either CU, CA, or CC). The public servants were transsformed (Figure 11) with the same patterns as that of the apathetic citizens only and the cooperating citizens only. The difference, however, is that this scenario resulted into having 50\% honest and 50\% dismissed public servants. 


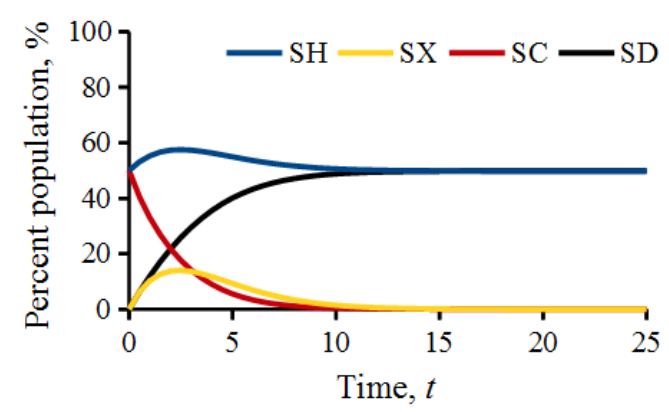

Figure 11. The effect of whistleblowing citizens on the time evolution among public servants.

\section{SUMMARY}

Presented in this paper is a model that treats corruption as an infectious disease that can infect both the public servants and the citizens through their interaction with one another. The corruption is in the form of bribery, which comes in two types depending on who initiated the action: Harassment bribery if initiated by the public servant and collusive bribery (or facilitation payment) if initiated by the citizen. The model only considered that of harassment bribery which involves public servants that are honest, on a crossroads, corrupt, and dismissed, the former three of which interact with the citizens who are upright, apathetic, cooperator, and whistleblower. The dynamics of the interaction between the public servant types and the citizen types are described mathamatically by a system of eight ODEs with twenty coefficients that quantify the rates of transformation from one type to the next. The five rates described in Table 1 provide quantification to the transformation among public servants when they interact with one another, while the six rates listed in Table 2 provide for that among citizens. Nine rates (Table 3 ) provide for the transformation between the public servants and the citizens.

The choice of a combination of the transformation rates can describe specific public policy or prevailing cultural pressure. Some results describe in the paper are when all the transformation rates were set to 0.5 , which may or may not describe specific policy or prevailing culture. An example model application, which is considered a trivial solution, is when the community is utopian: All public servants are honest and all citizens are upright. The utopian solution is considered at an equilibrium. The model shows stability when perturbed with a small percentage of corrupt public servants, that is the result goes back to utopoan equilibrium when the corrupt ones were ultimately dismissed from the service. The results always show equilibrium status.

The investigation on the effect of initially "seeding" the population with apathetic only, cooperating only, and whistleblowing only citizens to $50 \%$ honest and $50 \%$ corrupt public servants show the same patterns of time evolution of transformations among the public servants. The only difference is that starting with apathetic citizens results (in the equilibrium status) into having honest public servants slightly less at $47 \%$ than when it started but with more dismissed public servants at $30 \%$, while the apathetic citizens eventually transformed into upright ones. Starting with cooperating citizens results to having slightly more honest public servant at $55 \%$ but with less dismissed servants at $20 \%$, with the cooperating citizens eventually transforming into whistleblowing ones. Starting with whistleblowing citizens results to having the same percentage of public servant at $50 \%$ but with more dismissed servants at $50 \%$, with no 
transformation that happened to the citizens.

\section{RECOMMENDATIONS AND DISCLAIMER}

In the point of view of a scientific research, bribery in public service is hard to quantify with minimal observation bias, e.g., Hawthorne Effect (McCarney, et al., 2007). For one, bribery happens in secret, and the proverbial under-the-table transactions do not really happen as literally under the table nowadays. Such activities are now conducted with the aid of people's creative misuse (Greycar and Smith, 2012; ReSPA, 2013) of the advancements in information and communication technologies (ICT). Because corrupt activities happen in secrecy, most researches involving corruption were conducted either in laboratory settings or through selfreporting via anonymous surveys, both can contain unquantifiable biases. The model in this paper is just but one tool towards understanding the dynamics of social communities using mathematics and physics under a field of study called sociophysics (Ball, 2002). The knowledge gained in this multidisciplinary field can augment the search for understanding by social scientists, political scientists, physicists, mathematicians, and computer scientists, among others.

The utility of the model presented in this paper is countless. One may use it to ask what-if scenarios, with the combination of the twenty transformation rates and eight initial conditions as mathematical descriptions (or approximations) to a public policy or cultural environment in question. The combination of transformation rates that were used in this paper is but just one among the infinitely many combinations possible. The use of the model can aid students in understanding the nature of corruption in the public service, as well as policy researchers in crafting policies and programs to improve public service and governance. The model can be used by researchers to craft experiments, specially social experiments where biases such as Hawthorne Effect are hard to observe, quantify, and reduce, much so eliminate. It is very important to underscore that the model may be used as a tool only for understanding, and not to misuse it, for example as a justification for advancing certain governance policies and/or political agenda.

\section{ACKNOWLEDGMENTS}

A part of this study was funded by the 2018 UPLB Basic Research Program under the R\&D project entitled Mathematical Modeling and Computer Simulation of Fictional Epidemiological Events. Another part of this study was funded by the Institute of Computer Science (ICS) core fund under fund code 2326103.

\section{REFERENCES}

Abbink K. 2004. Staff rotation as an anti-corruption policy: An experimental study. European Journal of Political Economy 20(4):887-906 (doi: 10.1016/j.ejpoleco.2003.10.008).

Abbink K. 2006. Laboratory experiments on corruption. In S Rose-Ackerman (ed) International Handbook on the Economics of Corruption. Edward Elgar Publishing: Northampton, UK. pp. 418-437.

Abbink K, Dasgupta U, Gangadharan L and Jain T. 2014. Letting the briber go free: An experiment on mitigating harassment bribes. Journal of Public Economics 111:17-28 (doi: 10.1016/j.jpubeco.2013.12.012). 
Abbink K and Hennig-Schmidt H. 2006. Neutral versus loaded instructions in a bribery experiment. Experimental Economics 9(2):103-121 (doi: 10.1007/s10683-006-5385-z).

Abbink K, Irlenbusch B and Renner E. 2002. An experimental bribery game. Journal of Law, Economics and Organization 18(2):428-454 (doi: 10.1093/jleo/18.2.428).

Act No. 3815. 1930. An Act Revising the Penal Code and Other Penal Laws (The Revised Penal Code).

Alatas V, Cameron LA, Chaudhuri A, Erkal N and Gangadharan L. 2009. Gender, culture, and corruption: Insights from an experimental analysis. Southern Economic Journal 75(3):663-680.

Ball P. 2002. The physical modelling of society: A historical perspective. Physica A 314(1-4):1-14 (doi: 10.1016/s0378-4371(02)01042-7).

Banerjee A and Yakovenko VM. 2010. Universal patterns of inequality. New Journal of Physics 12:075032 (doi: 10.1088/1367-2630/12/7/075032).

Banuri S and Eckel CC. 2012. Chapter 3: Experiments in Culture and Corruption: A Review. In D Serra and L Wantchekon (ed.s) New Advances in Experimental Research on Corruption (Research in Experimental Economics, Volume 15) Emerald Group Publishing Limited, pp 51-76 (doi: 10.1108/S01932306(2012)0000015005).

Banuri S, Eckel CC and Wilson R. 2010. Experimental bribery in context: Comparing the U.S. and Pakistan. Center for Behavioural and Experimental Economic Science. Work Paper $09-01$.

Baron J. 2007. Thinking and Deciding, 4th ed. Cambridge University Press: New York, NY. pp 600 (ISBN 0521680433).

Barr A and Serra D. 2009. The effects of externalities and framing on bribery in a petty corruption experiment. Experimental Economics 12(4):488-503 (doi: 10.1007/s10683-009-9225-9).

Basu K. 2011. Why, for a Class of Bribes, the Act of Giving a Bribe should be Treated as Legal? (Available: http://www.mof.gov.in/).

Cameron L, Chaudhuri A, Erkal N and Gangadharan L. 2009. Propensities to engage in and punish corrupt behavior: Experimental evidence from Australia, India, Indonesia and Singapore. Journal of Public Economics 93(7-8):843-851 (doi: 10.1016/j.jpubeco.2009.03. 004).

Dicker RC, Coronado F, Koo Denise and Parish RG. 2006. Principles of Epidemiology in Public Health Practice, 3rd edition, An Introduction to Applied Epidemiology and Biostatistics. Self-Study Course SS1978. Centers for Disease Control and Prevention, U.S. Department of Health and Human Services. pp 511.

Civil Service Commission. 2010. Inventory of Government Personnel.

Corruption Perceptions Index — Results. 2018. (Available: http://www.transparency.org/ cpi2018/results).

Darley JM and Latane B. 1968. Bystander intervention in emergencies: Diffusion of responsibility. Journal of Personality and Social Psychology 8(4):377-383 (doi:10.1037/h0025589).

Di Matteo T, Aste T and Hyde ST. 2004. Exchanges in complex networks: Income and wealth distributions. In Mallamace F and Stanley HE (eds) The Physics of Complex Systems (New Advances and Perspectives). Societá Italiana di Fisica, Amsterdam: IOS Press, Proceedings of the International School of Physics Enrico Fermi, pp. 435-442.

Dreze J. 2011. The Bribing Game. Indian Express 17-19.

Dufwenberg M and Spagnolo G. 2011. Legalizing Bribes. Einaudi Institute for Economics and Finance (EIEF). Available: http://econpapers.repec.org/RePEc:eie:wpaper:1117.

Eicher S. 2009. Corruption in International Business: The Challenge of Cultural and Legal Diversity. Gower 
Publishing, Ltd.: Farnham, UK. pp 238 (ISBN: 9780754671374).

Engel C, Goerg SJ, and Yu G. 2013. Symmetric vs. Asymmetric Punishment Regimes for Bribery. Max Planck Institute for Research on Collective Goods Preprint, No. 2012/1 (doi: 10.2139/ssrn.1983969).

Ericta C. 2013. Filipino Families in the Poorest Decile Earn Six Thousand Pesos Monthly, on Average in 2012 (Results from the 2012 Family Income and Expenditure Survey). Philippine Statistical Administration Reference Number 2013-186.

Fehlberg E. 1969. Low order Runge-Kutta formulas with step control for heat transfer problems. Technical Report TR-R-315, NASA Marshall Space Flight Center, Huntsville, AL, pp. 46.

Frauenthal JC. 1980. Mathematical Modeling in Epidemiology. Springer-Verlag: Berlin. pp. 120 (doi: 10.1007/9783-642-67795-3).

Gans-Morse J, Borges M, Makarin A, Blankson TM, Nickow A and Zhang D. 2017. Reducing Bureaucratic Corruption: Interdisciplnary Perspectives on What Works. Working Paper WP-17-20, Institute for Policy Research, Northwestern University, Evanston, IL 60208, USA.

Gascoigne C and Fajan EJ. 2014. US\$410.5bn in Illegal Money Flowed in or out of Philippines from 1960-2011, Finds New GFI Study. Global Financial Integrity:Washington, DC.

Global Financial Integrity. 2018. (Accessed: http://www.gfintegrity.org/issue/illicit-financial-flows/).

Kar D and LeBlanc B. 2014. Illicit Financial Flows to and from the Philippines: A Study in Dynamic Simulation, 1960-2011. Global Financial Integrity:Washington, DC. pp 56.

Kar D and Spanjers J. 2015. Illicit Financial Flows from Developing Countries: 2004-2013. Global Financial Integrity:Washington, DC. pp 72.

Kermack WO and McKendrick AG. 1927. A contribution to the mathematical theory of epidemics. Proceedings of the Royal Society A 115(772):700-721 (doi:10.1098/rspa.1927.0118).

Liu X and Zeng YM. 2017. Stability Analysis of Analytical and Numerical Solutions to Nonlinear Delay Differential Equations with Variable Impulses. Discrete Dynamics in Nature and Society 2017:6723491-8 (doi: 10.1155/2017/6723491).

Mason M, Dyer R and Norton M. 2009. Neural mechanisms of social influence. Organizational Behavior and Human Decision Processes 110(2):152-159 (doi:10.1016/j.obhdp.2009.04.001).

McCarney R, Warner J, Iliffe S, van Haselen R, Griffin M and Fisher P. 2007. The Hawthorne Effect: A randomised, controlled trial. BMC Medical Research Methodology 7:30 (doi: 10.1186/1471-2288-7-30).

Munz P, Hudea I, Imad J and Smith? RJ. 2009. When Zombies Attack!: Mathematical Modeling of an Outbreak of Zombie Infection. In Tchenche JM and Chiyaka C (eds) Infectious Disease Modeling Research Progress, 133-150.

Office of the Ombudsman. 2014. 2013 National Household Survey on Experience with Corruption in the Philippines. Research and Special Studies Bureau, Office of the Ombudsman. pp 33.

Pabico JP. 2017a. Human-Borg dynamics during a cybernetic alien invasion. In 2017 Mathematical Society of the Philippines-CALABARZON Annual Regional Convention (MSPC 2017), First Asia Institute of Technology and Humanities, Tanauan City, Batangas, 23 September 2017 (doi: 10.7287/peerj.preprints.3198v1).

Pabico JP. 2017b. Ang epidemyolohiya ng aswang: Mga modelong matematikal at computer simulation. In 10 th UPLB CAS Student-Faculty Research Conference (SFRC 2017), NCAS Auditorium, UPLB, 20 November 2017.

Pabico JP. 2017c. An epidemiological model of drug addiction. In 2017 MSP Cebu Research Congress and 
Convention (MSP Cebu 2017), St. Mark Hotel, Queens Road, Kamputhaw, Cebu City, 8-9 December 2017.

Pabico JP. 2018a. Generalizing S-I-R for non-terminal epidemiological events. In 53rd BIOTA Annual National Convention and Scientific Sessions (BIOTA 2018), University of San Agustin, Iloilo City, Iloilo, 5-7 April 2018.

Pabico JP. 2018b. Stability analysis of a model for the propagation of corruption. Working Paper, Research Collaboratory for Advanced Intelligent Systems, Institute of Computer Science, University of the Philippines Los Baños.

Plous S. 1993. The Psychology of Judgment and Decision Making. McGraw-Hill:New York, NY. pp 302 (ISBN 0070504776).

R.A. 10147. Republic Act 10147: General Appropriations Act Fiscal Year 2011. Official Gazette of the Republic of the Philippines 106(52):1286. National Printing Office: Quezon City, MM (ISSN: 0115-0421).

Rey A. 2016. In Numbers: Impact of Corruption on the Philippines. Rappler.com.

Reycar A and Smith R (eds). 2012. Handbook of Global Research and Practice in Corruption. Edward Elgar Publishing:Cheltenham, UK. pp 520 (ISBN: 1849805016).

ReSPA. 2013. Abuse of Information Technology (IT) for Corruption. Regional School of Public Administration (ReSPA), Branelovica, Danilovgrad, Montenegro. pp 184.

Ryvkin D and Serra D. 2013. Does Competition Among Public Officials Reduce Corruption? An Experiment. Working Paper. Nova School of Business and Economics, Faculdade de Economia, Universidade Nova de Lisboa, Campus de Campolide, 1099-032 Lisboa, Portugal.

Ryvkin D and Serra D. 2018. Corruption and competition among bureaucrats: An experimental study. Journal of Economic Behavior and Organization (in press) (doi: 10.1016/j.jebo.2017.12.026).

Serra D. 2011. Combining top-down and bottom-up accountability: Evidence from a bribery experiment. Journal of Law, Economics and Organization 28(3):569-587 (doi: 10.1093/jleo/ewr010).

Serra D and Wantchekon L. 2012. New Advances in Experimental Research on Corruption. Emerald Group Publishing Limited. pp 300.

Schickora JT. 2011. Bringing the Four-Eyes-Principle to the Lab. Munich Discussion Papers in Economics 2011-3.

Smith? RJ. 2014a. Mathematical Modeling of Zombies. University of Ottawa Press: Ottawa, Canada. pp. 468 (ISBN: 0776622102).

Smith? RJ. 2014b. The Viral Spread of a Zombie Media Story. In Smith? RJ (ed.) Mathematical Modeling of Zombies, pp 1-26.

Souma W. 2001. Universal structure of the personal income distribution. Fractals 9(4):463-470 (doi: 10.1142/S0218348X01000816).

United Nations Development Programme. 1992. Human Development Report 1992. Oxford University Press: Oxford. pp 139 (ISBN: 0-19-507773-3).

Verma P and Sengupta S. 2015. Bribe and punishment: An evolutionary game-theoretic analysis of bribery. PLoS ONE 10(7):e0133441. doi:10.1371/journal.pone.0133441. 